\title{
A digitalização tridimensional como método de verificação da deformação do MDF ocasionada pela absorção de água
}

Three-dimensional scanning as verification method of
MDF deformation caused by water absorption

Eliana Paula Calegari ${ }^{1}$

Viviane Marcello Pupim²

Mário André Leal ${ }^{3}$

Fábio Pinto da Silva ${ }^{4}$ 


\section{Resumo}

A digitalização tridimensional consiste na captura de dados de superfícies, e a partir disso, a reconstrução de objetos em modelos 3D virtuais. Neste trabalho, a digitalização tridimensional foi aplicada na caracterização de materiais, tendo como objetivo avaliar o potencial dessa técnica para evidenciar a deformação em materiais ocasionada pela absorção de água. Para isso, foram confeccionados corpos de prova de MDF de duas marcas diferentes e realizado o ensaio de absorção de água conforme norma. Os resultados apontam que a digitalização tridimensional pode ser utilizada como método de verificação da deformação de materiais submetidos ao ensaio de absorção de água.

Palavras-Chave: Digitalização Tridimensional, Absorção de Água, MDF, Design de Produto.
Three-dimensional scanning consists of capturing surfaces data, and from that, a reconstruction of virtual 3D models. Therefore, in this work, a three-dimensional scanning was applied to the characterization of materials, aiming to evaluate the potential of the technique to evidence the deformation in materials caused by water absorption. MDF specimens of two different brands were made and the water absorption test was carried out according to the standard. The results point that the three-dimensional digitization can be used as a verification method of materials submitted to the water absorption test.

Keywords: 3D Scanning, Water Absorption, MDF, Product Design.

ISSN: 1808.3129

1 elianapaulac@gmail.com

2 vivianepupim@hotmail.com

3 designer.mario@gmail.com

4 fabio.silva@ufrgs.br 


\section{INTRODUÇÃO}

Os materiais possuem propriedades específicas que os diferenciam uns dos outros e estão diretamente relacionadas com a determinação das aplicações adequadas para cada tipo de material. Segundo Ashby e Johnson (2010) é de extrema importância o conhecimento das propriedades no processo de seleção de materiais no design de produto. Em consonância, Ferrante e Walter (2010) ressaltam que é fundamental conhecer as propriedades dos materiais para realizar a escolha apropriada, pois as mais relevantes para determinado produto dependem dos requisitos de projeto e das condições de trabalho. Para Karana et al. (2007) os materiais devem cumprir requisitos funcionais por meio das propriedades técnicas para uso destinado e também recorrer aos sentidos do usuário com suas propriedades sensoriais.

Propriedade de um material pode ser entendida como o tipo e a magnitude de resposta a um específico estímulo conferido. As propriedades de materiais sólidos podem ser agrupadas em seis diferentes categorias: mecânica, elétrica, térmica, magnética, ótica, e deteriorativa. Para cada propriedade existe um tipo característico de estímulo capaz de provocar diferentes respostas, como as propriedades mecânicas que relacionam deformação a uma carga ou força aplicada, exemplos incluem o módulo de elasticidade e a resistência mecânica (CALLISTER, 2006). Para a verificação de propriedades dos materiais são realizados ensaios específicos que seguem normas estabelecidas. Em relação à determinação da absorção de água, realiza-se o ensaio de absorção de água, importante propriedade para materiais cujas aplicações estejam em contato com umidade e água.

Devido à dificuldade de medição da forma de materiais irregulares para a determinação do inchamento em volume de materiais submetidos ao ensaio de absorção de água, este trabalho objetiva avaliar o potencial da técnica de digitalização tridimensional evidenciar a deformação dos materiais provocada pela absorção de água. A digitalização tridimensional é uma técnica utilizada para capturar imagens e dados de objetos em três dimensões, com o auxílio de ferramentas computacionais é possível capturar imagens em alta resolução e precisão de informações da forma, e também de detalhes da superfície e suas variações, permitindo também obter com grande precisão, curvas, detalhes de superfícies e texturas (BORGEAT et al., 2007).

Essa tecnologia possui diversas aplicações, como: a produção de roupas, calçados e próteses personalizadas, criação de dados 3D de modelos para animação, jogos e filmes, reprodução de peças de arte como esculturas, na engenharia reversa, entre outros. Assim, a técnica da digitalização tridimensional é capaz de proporcionar diferencial para o desenvolvimento de produtos, criando novas possibilidades para o design (SILVA et al., 2010).

Desse modo, para verificar a eficácia desta técnica foram utilizados corpos de prova de MDF (Painel de Média Densidade) submetidos ao ensaio de absorção de água. A escolha deste material é justificada pelo fato de possuir a característica de inchar quando submetido a condições de umidade, ou seja, as fibras incham e afetam o material, principalmente, em painéis de MDF cru que não possuem revestimento para proteção. Além disso, este material é de fácil usinagem e encontrado no mercado local. Assim, busca-se analisar o inchamento do MDF cru, quando submetido ao ensaio de absorção de água, utilizando a técnica de digitalização tridimensional a laser. 


\section{PAINEL DE MÉDIA DENSIDADE (MDF)}

A madeira está entre os primeiros materiais utilizados pelos seres humanos, há registros de restos de fogueiras associadas a agrupamentos com mais de 16 mil anos (GONZAGA, 2006). Apesar de todo o avanço na engenharia de materiais, especialmente no que se refere ao desenvolvimento de materiais sintéticos, a madeira ainda hoje é uma das principais matérias-primas de fonte renovável utilizada nas mais diversas áreas de produção de bens de consumo. Com o aumento da demanda, tornou-se escassa em diversos locais na medida em que as florestas foram dizimadas e às plantadas compreendem um ciclo que demora dezenas de anos para o seu crescimento, o que acabou restringindo o uso da madeira maciça. Esse contexto induziu a pesquisa por novas alternativas, e um dos materiais mais bem-sucedidos neste sentido tem sido o MDF, que consiste em um compósito desenvolvido para substituir a madeira, principalmente na fabricação de móveis.

Conforme a ABIPA (2015) o painel de MDF é produzido a partir das fibras da madeira aglutinadas com resina sintética através da aplicação de alta temperatura e pressão. Possui um aspecto compacto que o torna parecido com as características da madeira maciça, pois as fibras, componentes básicos da madeira, são similares, além da sua alta densidade. Outro aspecto favorável é o aproveitamento de resíduos oriundos de processos produtivos que utilizam a madeira como matéria-prima. Para Eleotério (2000), a utilização de painéis a base de madeira permite manter muitas das vantagens da madeira sólida, acrescentando outras, como: as dimensões dos painéis não são estritamente relacionadas às dimensões das árvores; é possível agregar valor a materiais de baixa aceitação como resíduos de serrarias; a possibilidade de eliminação de defeitos oriundos da anatomia da árvore como nós, medulas, desvios de grã, conferindo ao produto final homogeneidade muito maior que a encontrada na madeira serrada. Além disso, por meio da especificação da densidade, é possível controlar a maioria das propriedades acrescentando produtos específicos, aumentando assim a resistência dos painéis ao fogo e à deterioração.

Saldanha (2004) salienta que a importância do setor de painéis de madeira reconstituída pode ser atribuída aos seguintes fatores: a necessidade do uso racional dos recursos florestais, as restrições no uso e comercialização de madeiras nativas, além do melhor aproveitamento da matéria-prima resultante do processamento da madeira, o que pode fortalecer as indústrias de painéis reconstituídos que utilizam exclusivamente madeiras de florestas plantadas, sendo na sua maioria dos gêneros Pinus e Eucalyptus.

Desse modo, o MDF é um painel cuja característica principal é a sua grande estabilidade dimensional e a possibilidade de usinagem em diferentes formas, tanto nas bordas, quanto nas faces. Devido à densidade proporcionada pela homogeneidade do material, o painel de MDF pode ser facilmente pintado e revestido, torneado, entalhado e perfurado. Desta forma, o MDF é amplamente utilizado na indústria moveleira e na construção civil. Na indústria é bastante empregado em mobiliário, como, tampos de mesa, racks, estantes, frentes de gavetas, roupeiros, camas, com usinagens em bordas ou faces, e outros. Na construção civil é utilizado em pisos, rodapés, almofadas de portas, batentes, portas usinadas, e outros. Além disso, este material é 
empregado em interiores de lojas, em vitrines, como paredes, molduras arquitetônicas e outras aplicações. Cabe ressaltar que sua boa usinagem e características de acabamento são consideradas vantajosas (ABIPA, 2015).

Para Mattos et al. (2008) o segmento de painéis de madeira reconstituída, como o MDF, encontra-se em um cenário positivo no mercado brasileiro, visto que o aumento da oferta se direciona para o mercado interno, e o excedente pode ser absorvido pelo mercado externo. Neste contexto, o MDF, por ser um material retilíneo, difundiu-se na fabricação de móveis seriados, conforme aponta uma pesquisa realizada pela Associação das Indústrias de Móveis do Estado do Rio grande do Sul (MOVERGS), em que comprovou a importância do MDF na indústria moveleira. Os dados mostram que, com relação aos materiais utilizados pela indústria, os móveis de madeira e derivados respondem por $85 \%$ do total fabricado, tanto no país quanto no estado, e destes, os móveis seriados são a maioria, 73,2\% no Brasil, e $69,4 \%$ no Rio Grande do Sul (MOVERGS, 2015). O MDF, além de ter um aproveitamento superior na etapa de produção, também o tem no processo de beneficiamento e na manufatura dos produtos derivados. Quando se trabalha com madeira maciça a perda de material pode chegar a $50 \%$ do volume total, enquanto que com MDF e outros materiais derivados esse número é muito reduzido, ficando entre $10 \%$ e $20 \%$. A maior parte da perda de material se dá pela falta de conhecimento e planejamento, ou seja, em função da baixa qualidade da matéria-prima, falta de conhecimento das propriedades do material, falta de planejamento, plano de corte e aplicação de tecnologias inadequadas (CASSILHA et al., 2003).

Eleotério (2000) afirma que se o MDF for submetido a condições de umidade, as fibras podem inchar em um processo sistemático afetando a qualidade do material e danificando o painel e suas características. Este problema agrava-se ainda mais em painéis de MDF cru, pois não possuem revestimento para proteção. Assim, a qualidade do produto final pode ser comprometida devido à deformação do material que pode ser causada pela absorção de água.

\section{DIGITALIZAÇÃO TRIDIMENSIONAL}

Para Silva (2006) a digitalização tridimensional é utilizada basicamente para captar dados em três dimensões e, com auxílio de ferramentas computacionais, permite obter com grande precisão, detalhes de superfícies. Nos últimos anos os sistemas de digitalização tridimensional foram expressivamente melhorados, os métodos, as técnicas de obtenção de dados e as ferramentas computacionais evoluíram consideravelmente.

Existem diversos sistemas de digitalização, sendo os baseados em contato mais indicados para formas simples, pois poucos pontos são necessários. Conforme Freitas (2006) existem diversos sistemas de digitalização sem contato, como: triangulação por Laser, triangulação por cores, fotogrametria por conjuntos de câmeras CCD, fotogrametria por fotografias digitalizadas, radar Laser, tomografia, tunelamento, luz infravermelha com CCD linear e sensor conoscópico a Laser, este último utilizado neste trabalho. 
Para a obtenção de modelos 3D o processamento é realizado nos dados da nuvem de pontos adquirida. É importante realizar a filtragem dos pontos dessa nuvem, pois os arquivos tornam-se muitos pesados e de difícil manipulação em computadores convencionais. A filtragem de pontos pode ser realizada através de sistemas CAD (Computer Aided Design). Além disso, a filtragem de pontos é importante para reduzir os ruídos intrínsecos ao processo de digitalização, tornando também, o modelo mais fácil de manipular.

Conforme Freitas (2006), o bom resultado da digitalização depende, principalmente, da qualidade do equipamento de digitalização, da preparação da amostra e das condições externas de trabalho, como temperatura, vibrações, luminosidade, e outros. Silva (2006) salienta que por mais controlado que seja o processo, sempre haverá ruídos elétricos ou mecânicos, os quais poderão causar distorções indesejadas na nuvem de pontos, dessa forma, é necessária a filtragem da nuvem de pontos. A partir da nuvem de pontos filtrada, o sistema une os pontos de três em três gerando inúmeros triângulos planos, obtendo-se assim, uma malha tridimensional da superfície do objeto que foi digitalizado. $O$ arquivo gerado pode ser salvo no formato STL, que é padrão para os sistemas de prototipagem rápida e compatível com os principais sistemas CAM (Computer Aided Manufacturing) disponíveis no mercado (SILVA et al., 2010).

De acordo com Silva et al. (2010), a técnica de digitalização tridimensional a Laser vem sendo aplicada em várias áreas, como: o desenvolvimento de produto, a construção de moldes, no controle da qualidade, preservação do patrimônio público, e outros, que procuram tornar o setor produtivo mais flexível e ágil. Sendo, também, muito utilizada para o armazenamento virtual, que permite a redução de espaço físico e o transporte. Além disso, a digitalização tridimensional pode facilitar o desenvolvimento de produtos personalizados, pode ser aplicada na joalheria, no vestuário, na tecnologia assistiva, como ocorre em pesquisas realizadas no Laboratório de Design e Seleção de Materiais (LdSM) da Universidade Federal do Rio Grande do Sul.

Em relação à digitalização tridimensional aplicada a produtos personalizados, a pesquisa do grupo do LdSM focou na digitalização de faces humanas com o objetivo de desenvolver óculos personalizados que possam se adequar ao usuário (BERTOL et al., 2010). Na pesquisa sobre joalheria, foi digitalizada uma face humana e esta foi usinada na em rejeitos de opala branca e ágata, proveniente de atividade de mineração do município de Salto do Jacuí, RS/Brasil, para a produção de camafeus (TESSMANN, 2009). No trabalho sobre vestuário, foi realizado um estudo na área de roupas íntimas femininas, já que a digitalização tridimensional permite adquirir medidas corporais confiáveis e, assim, conhecer as variações nestas medidas pelo uso de sutiãs (KAGIYAMA, 2011). Este estudo buscou compreender a mudança da forma dos seios com o uso do sutiã através de medidas corporais obtidas através da digitalização tridimensional. Dessa forma, foi possível executar comparações de diferentes modelos de sutiãs com grande precisão. Outra importante aplicação da digitalização tridimensional, que foi foco de pesquisa no LdSM, foi na tecnologia assistiva. $O$ estudo baseou-se no desenvolvimento de assentos ortopédicos personalizados (SILVA et al., 2011). Também utilizou-se a técnica de digitalização para o projeto de um encosto diretamente do modelo virtual das costas do usuário (SILVA et al., 2010). Salienta-se 
que a técnica de digitalização não é invasiva, o que evita danos em objetos, como é o caso de objetos arqueológicos, em que a técnica permite a documentação e visualização digital de geometrias volumétricas (LERMA et al., 2010).

A digitalização 3D permite também que sejam realizadas medidas de desgaste, construção de moldes, análise de superfícies, para isso, geralmente, são utilizados sistemas de alta tecnologia, como o Scanner 3D e softwares CAD/CAM (SILVA, 2011). Assim, a digitalização tridimensional é uma técnica que auxilia diversas áreas para análise, inspeção, personalização, que repercutem na melhoria de produtos, conforme pesquisas relatadas neste trabalho. Ainda, esta técnica pode ser utilizada para a verificação de propriedades de materiais, como é o caso da proposta deste trabalho, que visa o emprego da digitalização tridimensional como ferramenta para verificar a deformação do MDF submetido ao ensaio de absorção de água.

\section{MATERIAIS E MÉTODOS}

A metodologia utilizada neste estudo parte da preparação dos corpos de prova de MDF, em que foram utilizadas duas marcas desse material. Na sequência, foi realizado o ensaio de absorção de água, de acordo com norma específica, e concomitantemente, foi realizada a medição de massa e a deformação provocada pelo inchamento das amostras que foi verificada através da digitalização tridimensional a laser.

\subsection{Confecção dos corpos de prova}

Para a produção dos corpos de prova foi utilizada a tecnologia da usinagem por comando numérico computacional (CNC), que é um processo de fabricação automatizado e pode produzir peças únicas. A usinagem é definida como um processo de fabricação utilizado para dar forma a um componente através da remoção de material. Para a usinagem é necessário programar o processo determinando o tipo de ferramenta (fresa) a ser utilizada, além dos parâmetros de corte, velocidade de rotação, velocidade de avanço, penetração de trabalho e profundidade de corte. Esse processo, proporciona aos objetos boa precisão dimensional e acabamento (FERRARESI, 1998).

Foram adquiridos retalhos de MDF cru (sem revestimento) de duas marcas, denominadas $A$ e $B$, com espessura de $30 \mathrm{~mm}$, provenientes da sobra do corte de chapas em marcenarias da cidade de Porto Alegre, RS/Brasil. Em relação à confecção dos corpos de prova, foi utilizado o processo de usinagem por comando numérico computacional (CNC), no equipamento do modelo Digimill 3D, marca Tecnodrill ${ }$, com uma fresadora CNC com três eixos de movimentação, que se encontra nas dependências do LdSM. Para a programação das estratégias de usinagem foi utilizado o software EdgeCAM. Inicialmente foi gerado um modelo virtual no software Rhinoceros, conforme ilustra a Figura 1. 


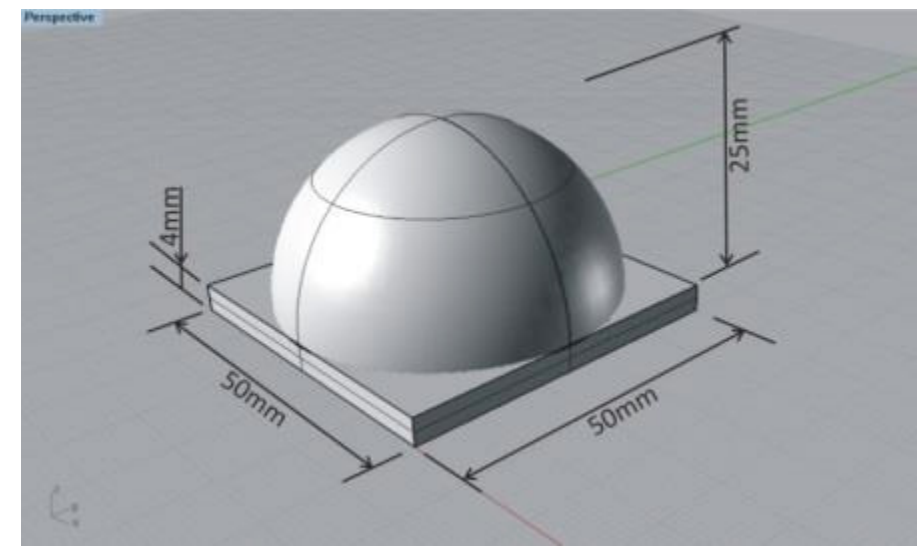

Figura 1: Modelagem tridimensional do corpo de prova com dimensões.

Fonte: Construção dos autores.

As ferramentas utilizadas para a usinagem foram uma fresa de topo reta para desbaste com $10 \mathrm{~mm}$ de diâmetro, e uma fresa de topo esférica para acabamento com $6 \mathrm{~mm}$ de diâmetro. Foram utilizados como parâmetros de corte a rotação de 14.000 RPM, a taxa de avanço de $4.000 \mathrm{~mm} / \mathrm{min}$ e as profundidades de corte máximas de $2 \mathrm{~mm}$ para desbaste e $2 \mathrm{~mm}$ para acabamento, a Figura 2 ilustra o processo da usinagem.
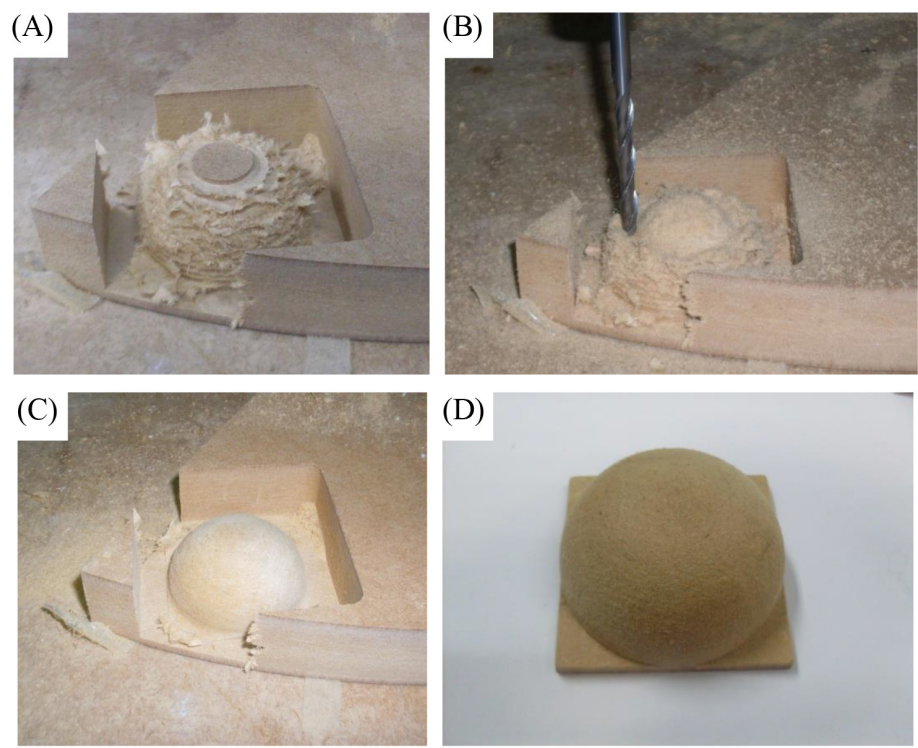

Figura 2: Processo de usinagem dos corpos de prova: A) Desbaste, B) Acabamento e C) Corpo de prova usinado, D) Corpo de prova finalizado.

Fonte: Construção dos autores.

Foram usinados três corpos de prova de cada marca e na sequência foram identificados. Foi necessário realizar marcações que servissem de referência para o processo de montagem das malhas dos pontos gerados pela digitalização tridimensional, assim, foram feitos rebaixos esféricos com furadeira nos quatro cantos de cada corpo de prova, como pode ser visto na Figura 3. 


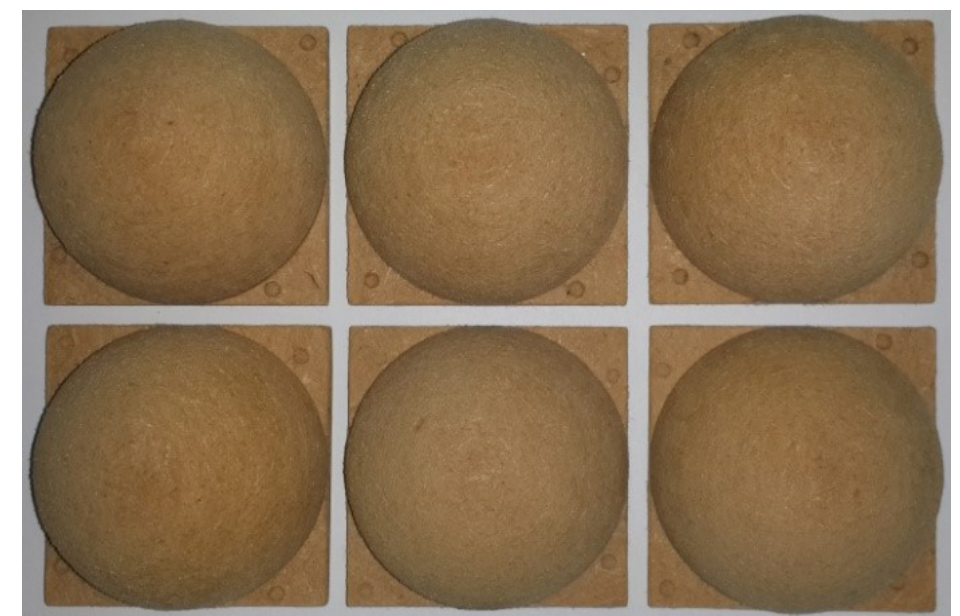

Figura 3: Corpos de prova: A) Corpos de prova da marca A e B) Corpos de prova da marca B.

Fonte: Construção dos autores.

\subsection{Ensaio de absorção de água}

Segundo a norma brasileira de MDF, ABNT NBR 15316-1, o ensaio de absorção de água consiste no aumento da massa (em água) que um corpo de prova de uma chapa de MDF apresenta, após ser imerso em água a $20 \pm 1^{\circ} \mathrm{C}$ pelo tempo de $24 \mathrm{~h} \pm$ $36 \mathrm{~min}$. Ainda segundo esta norma, o inchamento consiste na variação percentual de aumento em espessura que um corpo de prova de uma chapa de MDF apresenta após ficar imerso pelo tempo e temperatura citados.

Para Torquato (2008) as normas europeias estão entre as mais exigentes em relação ao uso de produtos a base de madeira, além de ser referência para os produtores brasileiros, são utilizadas para a execução do ensaio de absorção de água. Deste modo, a Norma EN 317 refere-se à determinação do inchamento após imersão em água.

Conforme esta norma, os corpos de prova devem possuir dimensões de 50 × 50 $\mathrm{mm}$, e inicialmente devem ser medidos e pesados em balança analítica. Em seguida, deve-se colocá-los em um recipiente contendo água fria destilada, à temperatura ambiente, conforme mostra a Figura 4. Após $2 \mathrm{~h}$ devem ser retirados, removido o excesso de água, e realizada novamente a pesagem e a medição da espessura. Na sequência, devem ser recolocados no recipiente com água por mais $22 \mathrm{~h}$ até completar às $24 \mathrm{~h}$ de imersão, e seus valores registrados para a definição da absorção de água do MDF.

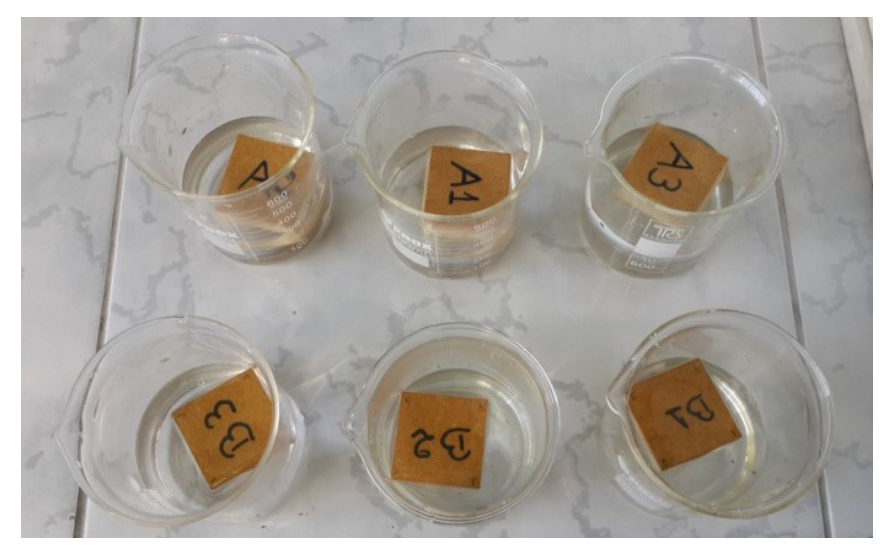

Figura 4: Corpos de prova em recipientes com água destilada. Fonte: Construção dos autores. 
Neste sentido, pelo fato dos corpos de prova possuírem forma irregular, e assim não ser possível utilizar métodos de medição convencional, estes foram digitalizados para verificar a deformação provocada pela absorção de água. Assim, os corpos de prova foram digitalizados e pesados, em balança digital da marca Quimis ${ }^{\circledR}$ modelo $\mathrm{Q}-500 \mathrm{~L} 210 \mathrm{C}$, antes de serem imersos na água e após $2 \mathrm{~h}$ e $22 \mathrm{~h}$ de imersão, para verificar o inchamento. Dessa forma, os valores de massa foram registrados e utilizou-se a seguinte fórmula para a definição da absorção de água: $A \%=100 \times(M 2-M 1) /$ M1, onde M1 é a massa inicial e M2 a massa final.

Para a obtenção dos modelos virtuais, os corpos de prova foram escaneados pela técnica de digitalização tridimensional a laser. No presente estudo utilizou-se o cabeçote de leitura a laser Conoprobe 1000, o qual é acoplado na máquina CNC Digimill 3D. O processo de digitalização consiste na varredura de uma superfície por um feixe de laser capaz de determinar a distância entre ele e o ponto sobre o qual incide. Assim, obtém-se a coordenada $z$, a qual possui precisão dependente da lente empregada. Utilizou-se uma lente de $150 \mathrm{~mm}$, as coordenadas $\mathrm{x}$ e y são fornecidas pelo programa CNC responsáveis pelo posicionamento do cabeçote laser. O cruzamento destes dados geram numerosos pontos no espaço tridimensional, denominados nuvem de pontos. O espaçamento entre estes pontos é chamado de resolução, sendo responsável pelo tempo de digitalização, os corpos de prova foram digitalizados com a resolução de 0,1 $\mathrm{mm}$.

O primeiro escaneamento foi feito antes da imersão em água destilada, neste, os corpos de prova foram escaneados de topo no tempo de $30 \mathrm{~min}$, a seguir, foram digitalizados todos os cantos de cada um, no tempo de 15 min de digitalização para cada canto, como pode ser visto na Figura 5.
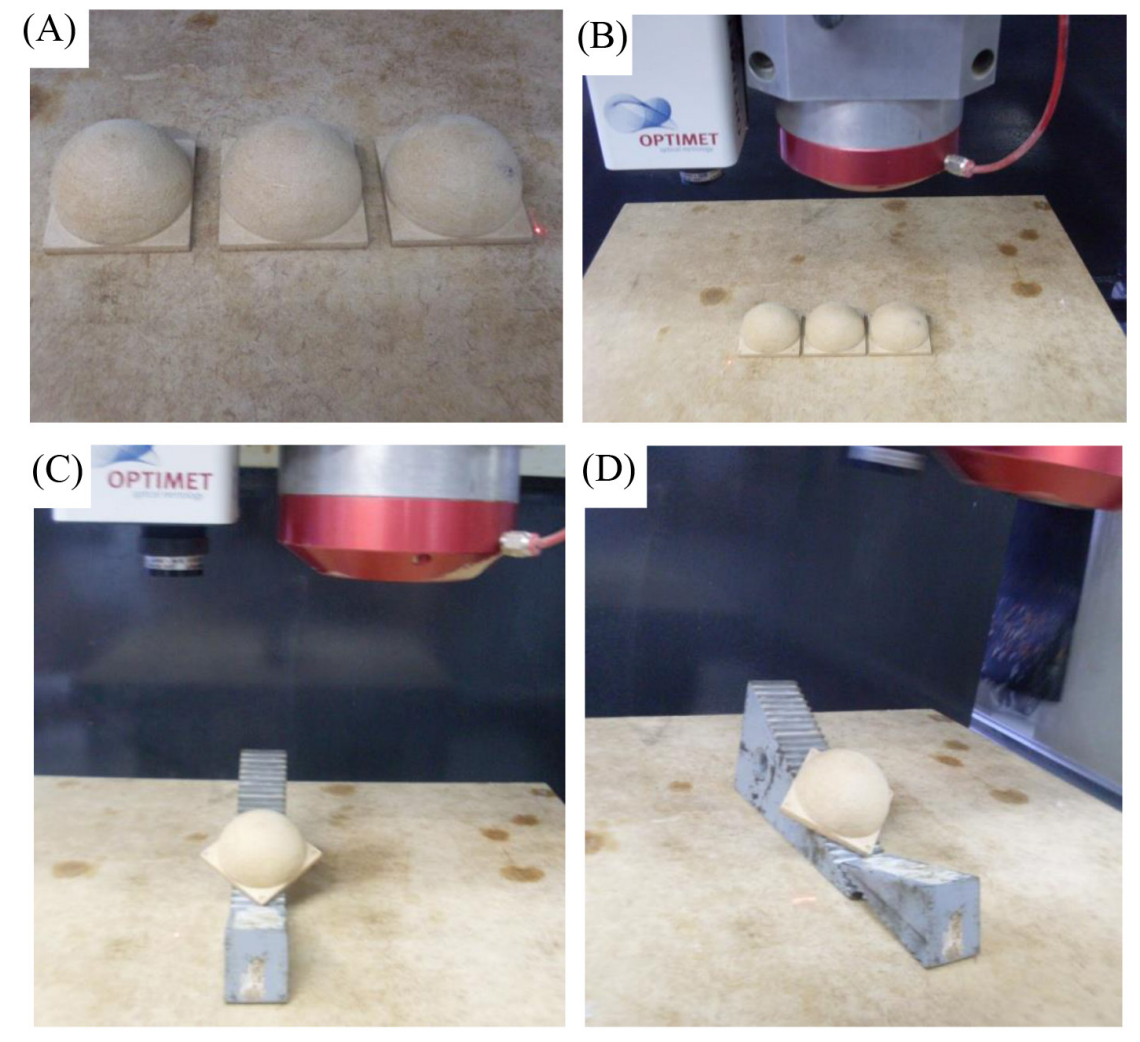

Figura 5: Digitalização dos corpos de prova: A) Posicionamento dos corpos de prova para a digitalização, B) Digitalização de topo antes da imersão, C) Digitalização dos cantos antes da imersão, D) Detalhe da inclinação do corpo de prova para a digitalização dos cantos.

Fonte: Construção dos autores. 
Após 2 h e 22 h de imersão, foi realizada novamente a digitalização, para isso, os corpos de prova foram colocados em uma bandeja acrílica com água para evitar que a mesa de MDF do equipamento digitalizador absorvesse a água dos corpos de prova alterando seu percentual de inchamento, como pode ser visualizado na Figura 6.

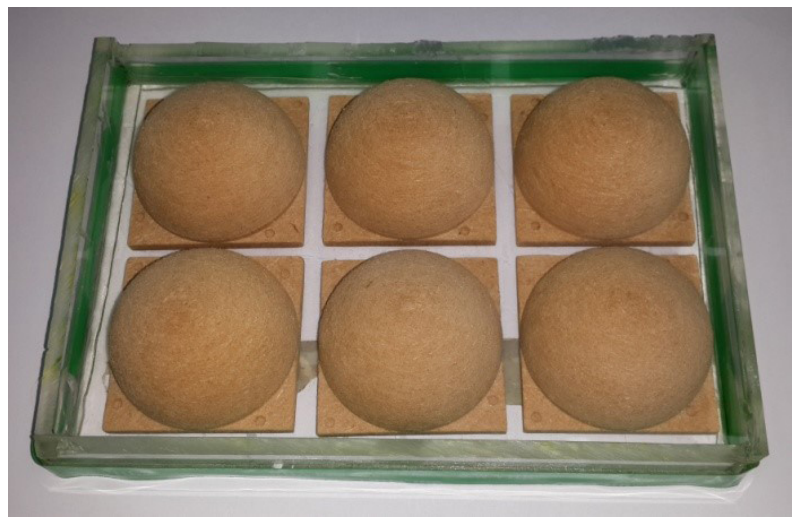

Figura 6: Corpos de prova em bandeja acrílica. Fonte: Construção dos autores.

Após a digitalização, as nuvens de pontos foram tratadas no software Geomagic Studio ${ }^{\mathrm{TM}}$, o qual as pré-processa. Posteriormente, utilizou-se o software Geomagic Qualify $^{\mathrm{TM}}$ para a realização da análise dimensional.

\section{RESULTADOS E DISCUSSÕES}

Os dados gerados pela digitalização tridimensional a laser possibilitaram a verificação da deformação dos corpos de prova de MDF submetidos ao ensaio de absorção de água. Com o auxílio do software Geomagic Qualify ${ }^{\top M}$, a nuvem de pontos obtida com o escaneamento dos corpos de prova antes da imersão, utilizada como referência, foi sobreposta à superfície dos corpos de prova submersos em água no período de $2 \mathrm{~h}$ e após $24 \mathrm{~h}$. Esta sobreposição das superfícies permite a visualização da deformidade ocorrida nos corpos de prova após 2 h e 24 h de imersão em água ocasionada pelo inchamento dos corpos e, pode ser observada na Figura 7 que ilustra a imagem em corte do corpo de prova.

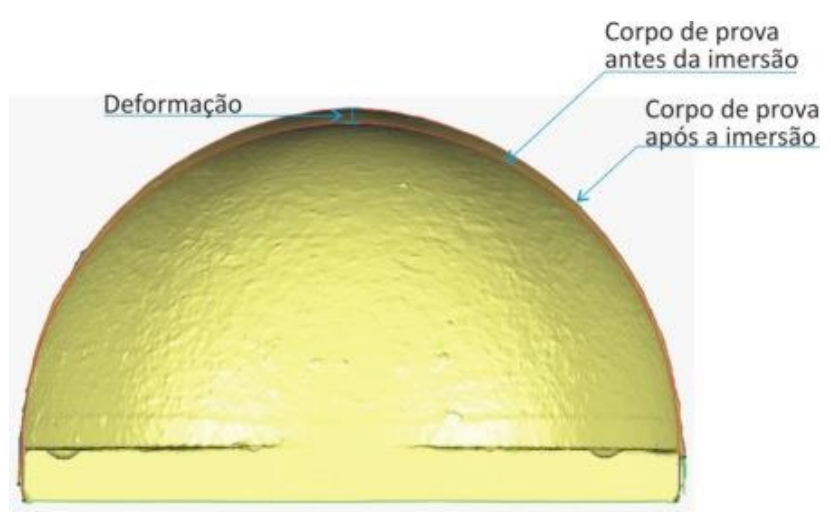

Figura 7: Vista em corte da sobreposição das superfícies digitalizadas dos corpos de prova e a deformação provocada pela absorção de água.

Fonte: Construção dos autores. 
A Figura 7 permite aferir que através da técnica de digitalização tridimensional é possível verificar a deformação ocorrida no MDF submetido ao ensaio de absorção de água. A partir da sobreposição das nuvens de pontos, o software permite calcular a distância média entre a superfície de referência, que consiste no corpo de prova antes da imersão, e a superfície digitalizada após 2 h e 24 h de imersão. Assim, com base em uma superfície de referência, utilizou-se uma escala em $\mathrm{mm}$ com cores indicativas dos pontos localizados abaixo (em tons de azul) e acima da superfície de referência (em tons avermelhados). A cor verde indica as regiões em que não houve deformação significativa $(<0.20 \mathrm{~mm})$, a Figura 8 ajuda a compreender o funcionamento desta escala e seus valores. Nos Quadros 1 e 2, pode-se visualizar a análise dimensional dos corpos de prova do MDF das marcas A e B.

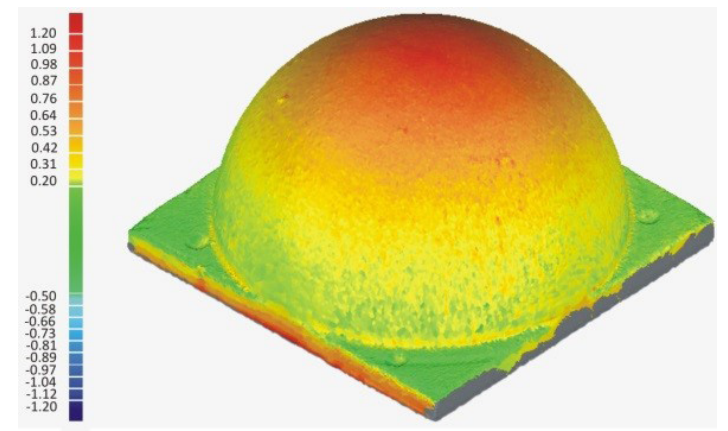

Figura 8: Ilustração da escala em mm e cores utilizada para evidenciar a sobreposição das superfícies digitalizadas dos corpos de prova e a deformação provocada pela absorção de água.

Fonte: Construção dos Autores.

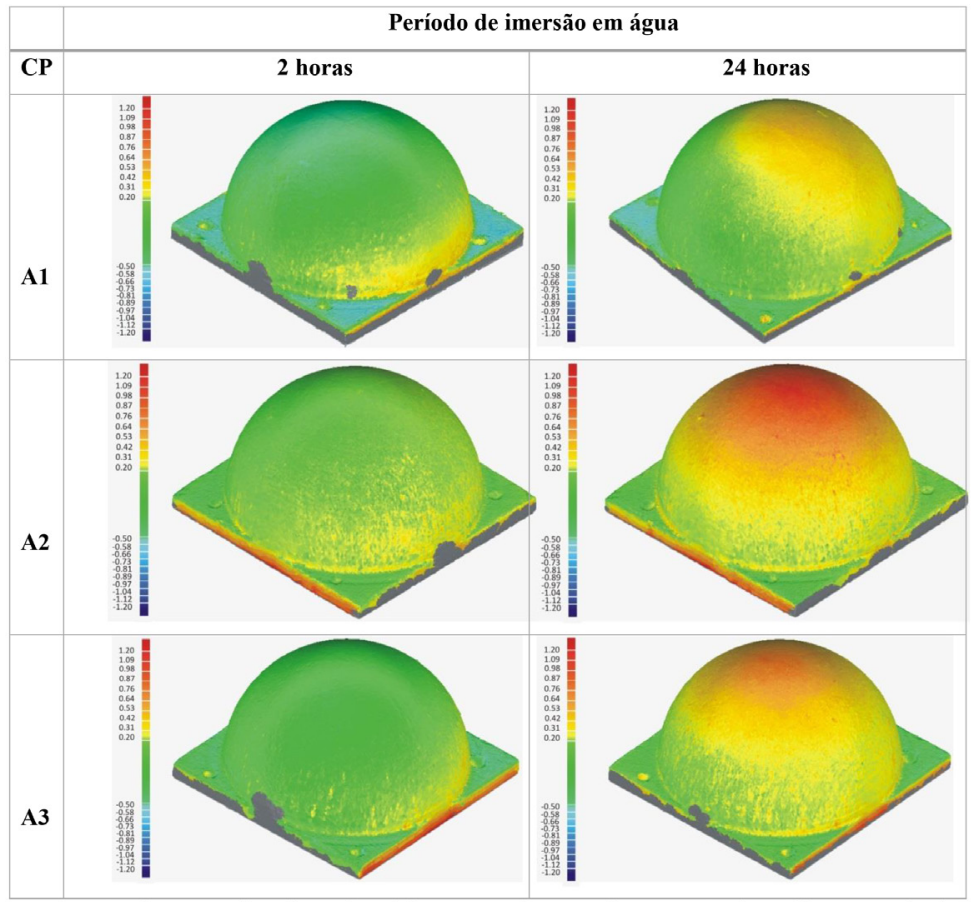

Quadro 1: Análise dimensional dos corpos de prova da marca A submetidos ao ensaio de absorção de água (escala em mm).

Fonte: Construção dos Autores. 


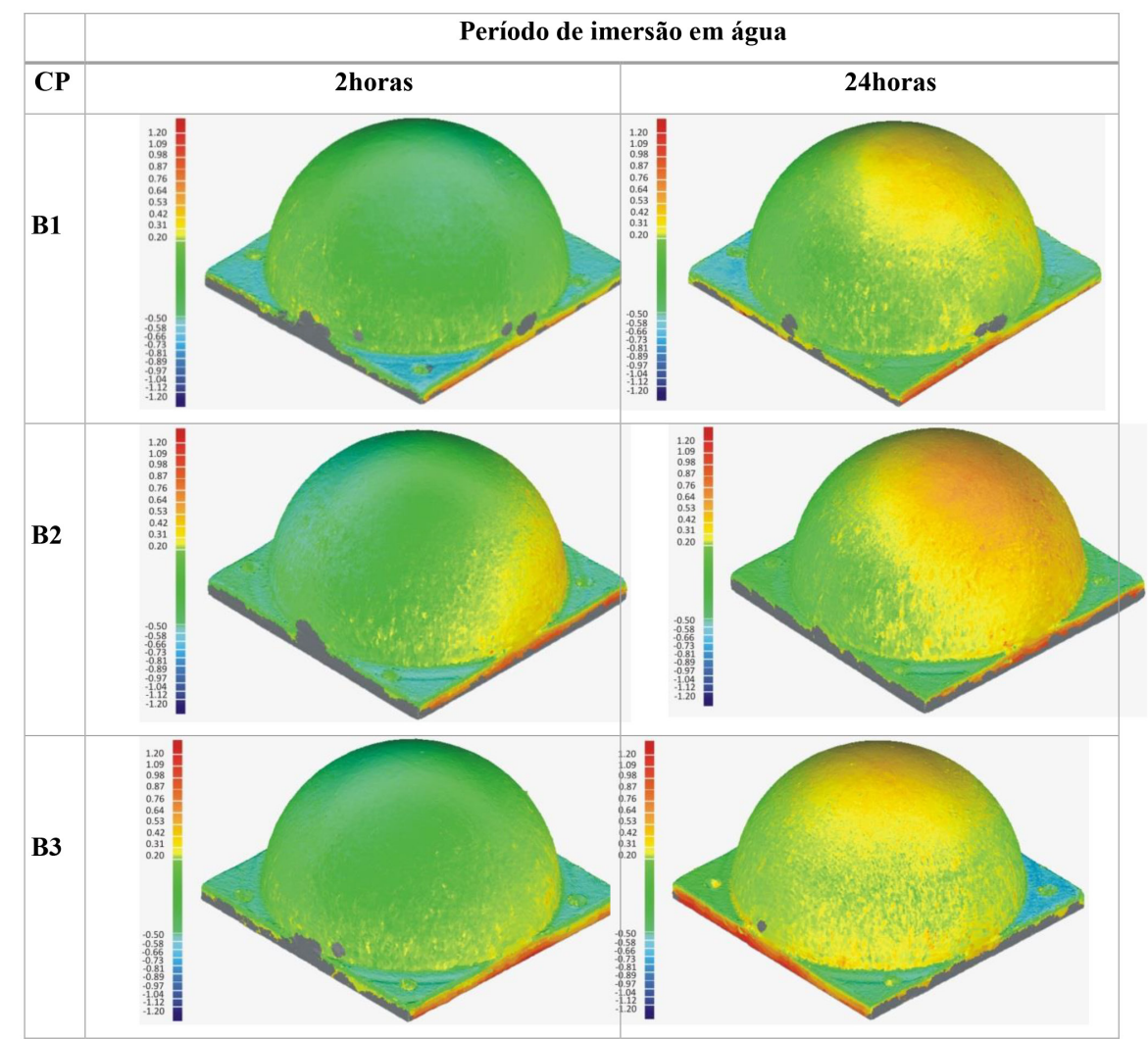

Quadro 2: Análise dimensional dos corpos de prova da marca B submetidos ao ensaio de absorção de água (escala em mm).

Fonte: Construção dos Autores.

Através das cores dos gráficos observa-se que os corpos de prova da marca $A$ foram os que mais deformaram, ou seja, incharam mais que os da marca B. Nota-se que os corpos de prova da marca $A$ absorveram maior quantidade de água, já que apresentaram ligeira maior porcentagem de absorção de água tanto nas $2 \mathrm{~h}$ como nas 24 h de imersão, conforme ilustra a Figura 9.

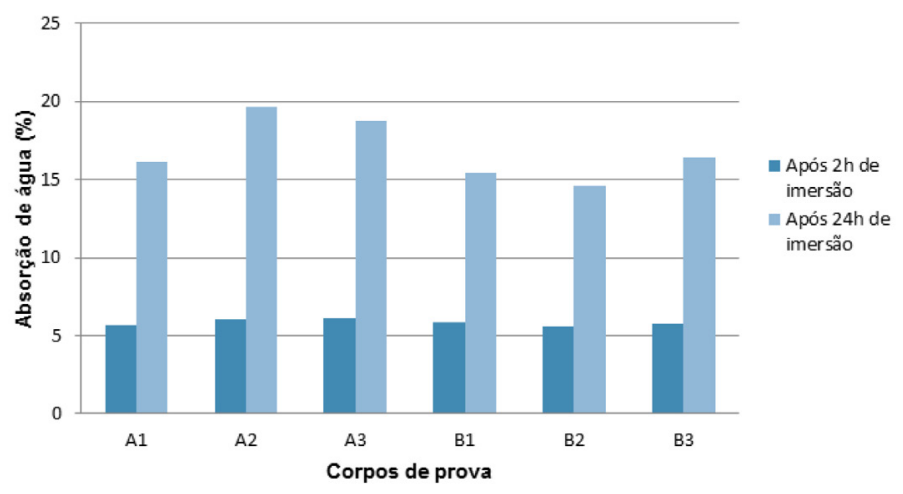

Figura 9: Absorção de água dos corpos de prova submetidos ao ensaio de absorção de água em função do tempo.

Fonte: Construção dos Autores.

Dessa forma, o experimento apontou que o MDF da marca A absorve ligeiramente mais água e por consequência ocorreram maiores deformações no material. Ainda, observa-se que os corpos de prova submetidos às $24 \mathrm{~h}$ de imersão possuem maiores deformações, ou seja, absorveram maior quantidade de água e com isso o 
nível de inchamento do material foi maior, assim, quanto maior o tempo de imersão, maior a deformação do MDF. Deste modo, a porcentagem de absorção de água e o inchamento são diretamente proporcionais, ou seja, quanto maior a absorção de água maior será o inchamento, o que está de acordo com o estudo de Eleotério (2000) que afirma que a absorção de água determina o inchamento, o que explica a correlação entre essas duas variáveis. Outra constatação ocorreu na análise das imagens sobrepostas em corte, em que se verificou que um lado dos corpos de prova possui menor inchamento em relação ao outro lado, como pode ser observado na Figura 10.

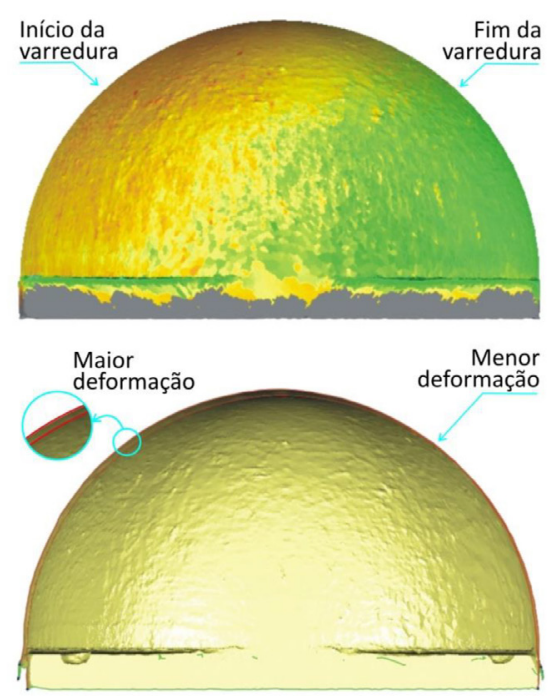

Figura 10: Indicação do início e fim da varredura do laser no corpo de prova e a respectiva deformação. Fonte: Construção dos Autores.

A diferença de inchamento entre os lados, possivelmente, deve-se ao fato do tempo que decorre o processo da digitalização, sendo assim, a parte em amarelo representa o lado em que foi iniciado o escaneamento e a parte em verde, o final da varredura do laser. Provavelmente, este desnivelamento, ocorreu devido à difusão e à evaporação da água durante o processo de escaneamento. Dessa forma, o escaneamento tridimensional pode também demonstrar a velocidade de perda de água dos corpos de prova submetidos à imersão em água, ou seja, a relação evaporação/ tempo/deformação.

\section{CONSIDERAÇÕES FINAIS}

Pode-se concluir que a digitalização 3D apresenta-se como uma técnica que vem a contribuir significativamente com a caracterização de materiais. Este estudo demonstrou que a digitalização tridimensional evidenciou a deformação de materiais em ensaio de absorção de água. A análise dimensional apontou a maior deformação nos corpos de prova da marca A do MDF, tanto nas $2 \mathrm{~h}$ como nas $24 \mathrm{~h}$ de imersão em água destilada. Este fato está relacionado com a porcentagem de absorção de água, assim, quanto maior a absorção de água, maior o inchamento e deformação dos corpos de prova.

Além disso, na análise dimensional, constatou-se um desnivelamento da de- 
formação nos corpos de prova, que pode ser ocasionado pela difusão e evaporação da água durante o processo de digitalização. Dessa forma, no gráfico gerado pelo software é possível observar o desinchamento, ou seja, a perda de água ocorrida durante o escaneamento, evidenciando a relação entre a perda de água, tempo e deformação.

Assim, esta pesquisa demonstrou que a digitalização tridimensional pode ser utilizada como método para verificação da deformação de materiais em ensaio de absorção de água. Dessa forma, este método torna-se interessante para materiais com formas irregulares, como os naturais. Além disso, devido ao fato deste estudo ter comprovado a deformação do MDF submetido ao ensaio de absorção de água, conclui-se que são necessárias pesquisas para a melhoria da qualidade do material frente à absorção de água, por exemplo, com a aplicação de vernizes seladores.

\section{REFERÊNCIAS}

ABIPA. Nossas unidades industriais. Disponível em: <http://www.abipa.org.br/ numeros.php>. Acesso em: 10 de nov. de 2015.

ABNT - ASSOCIAÇÃO BRASILERIA DE NORMAS TÉCNICAS. NBR 15316-1: Chapas de fibras de média densidade. Parte 1: Terminologia. Rio de Janeiro, 2006.

ASHBY, M. F.; JOHNSON, K. Materials and design: the art and science of material selection in product design. Amsterdam: Elsevier/Butterworth-Heinemann, 2010.

BERTOL, L. S.; BERETTA, E. M.; SENNA, C. E.; DUARTE, L. C.; KINDLEIN JUNIOR, W. A digitalização 3D a laser como ferramenta para a customização de armações de óculos. In: Congresso Brasileiro de Pesquisa e Desenvolvimento em Design. Anais. São Paulo, SP : AEND-BR, 2010.

CASSILHA, A. C.; et al. Indústria moveleira e resíduos sólidos: considerações para o equilíbrio ambiental. Revista Educação \& Tecnologia, 2003.

ELEOTÉRIO, J. R. Propriedades físicas de painéis MDF de diferentes densidades e teores de resina. (Dissertação de mestrado). Escola Superior de Agricultura "Luís de Queiroz", Universidade de São Paulo, Piracicaba, São Paulo, 2000.

EUROPEAN COMMITTEE FOR STANDARDIZATION. European Standard EN 317 - particleboards and Fiberboards - determination of swelling in thickness after immersion in water. Bruxelas, 1993.

FERRANTE, M.; WALTER, Y. A materialização da ideia: noções de materiais para design de produto. Rio de Janeiro: LTC, 2010.

FREITAS, G. Metodologia e aplicabilidade da digitalização 3D a laser no desenvolvimento de moldes para calçados e componentes. Dissertação de mestrado. PPGEM, Universidade Federal do Rio Grande do Sul, Porto Alegre, 2006. 2006.

GONZAGA, A. L. Madeira: uso e conservação. Brasília, DF: IPHAN/Monumenta,

KARANA, E.; HEKKERT, P.; KANDACHAR, P. Material considerations in product design: a survey on crucial material aspects used by product designers. Materials and Design, 2007.

KAGIYAMA, W. Design de vestuário íntimo: o sutiã sob a abordagem de conforto. (Mestrado em Design). Programa de Pós-Graduação em Design com ênfase em Design e Tecnologia, Universidade Federal do Rio Grande do Sul, Porto Alegre, 2011.

MOVERGS. Panorama do setor moveleiro no Brasil e RS - 2013. Disponível em: <http://www.movergs.com.br/views/imagem_pdf.php?pasta=panorama_setor_ moveleiro>. Acesso em 10 dez. 2015.

MATTOS, R. L. G.; GONÇALVES, R. M.; CHAGAS, F. B. Painéis de madeira no Brasil: panorama e perspectivas. BNDES Setorial, Rio de Janeiro, n. 27, p. 121-156, 2008.

SALDANHA, L. K. Alternativas tecnológicas para produção de chapas de partículas orientadas "OSB". Dissertação (Mestrado em Ciências Florestais)- Setor de Ciên- 
cias Agrárias, Universidade Federal do Paraná, Curitiba, 2004.

SILVA, F. P. O uso da Digitalização Tridimensional a Laser no Desenvolvimento e Caracterização de Texturas Aplicadas ao Design de Produtos. Dissertação de Mestrado. PPGEM, Universidade Federal do Rio Grande do Sul, Porto Alegre, 2006.

SILVA, F. P.; DUARTE, L. C.; ROLDO, L.; KINDLEIN, W. Jr. A Digitalização Tridimensional Móvel e sua aplicação no Design de Produto. Revista Design \& Tecnologia, p. 60-65, 2010.

SILVA, F. P.; BERETTA, E. M.; PRESTES, R. C.; KINDLEIN JUNIOR, W. Design and milling manufacture of polyurethane custom contoured cushions for wheelchair users. Australasian Medical Journal, v. 4, p. 500-506, 2011.

TESSMANN, C. S. Importância do binômio Design e Engenharia no beneficiamento do rejeito mineral de opala e ágata na produção de camafeus por usinagem CNC. (Mestrado em Design). Programa de Pós-Graduação em Design com ênfase em Design e Tecnologia, Universidade Federal do Rio Grande do Sul, Porto Alegre, 2009.

TORQUATO, L. P. Caracterização dos painéis MDF comerciais produzidos no Brasil. Dissertação de mestrado. Curso de Pós-Graduação em Engenharia Florestal, Setor de Ciências Agrárias, Universidade Federal do Paraná, Curitiba, 2008. 